\title{
THE
}

\section{The Impact of a Student-Run Journal Club on Pharmacy Students' Self-Assessment of Critical Appraisal Skills}

\author{
Macayla Landi \\ University of Rhode Island \\ Springer \\ University of Rhode Island \\ Erica Estus \\ University of Rhode Island, elestus@uri.edu \\ Kristina E. Ward \\ University of Rhode Island, kward@uri.edu
}

Follow this and additional works at: https://digitalcommons.uri.edu/php_facpubs

The University of Rhode Island Faculty have made this article openly available. Please let us know how Open Access to this research benefits you.

This is a pre-publication author manuscript of the final, published article.

Terms of Use

This article is made available under the terms and conditions applicable towards Open Access

Policy Articles, as set forth in our Terms of Use.

\section{Citation/Publisher Attribution}

Landi, M., Springer, S., Estus, E., \& Ward, K. (2015). The Impact of a Student-Run Journal Club on Pharmacy Students' Self-Assessment of Critical Appraisal Skills. The Consultant Pharmacist, 30(6), 356-360. doi: 10.4140/TCP.n.2015.356

Available at: http://dx.doi.org/10.4140/TCP.n.2015.356 


\title{
The Impact of a Student-Run Journal Club on Pharmacy Students' Self-Assessment of Critical Appraisal Skills
}

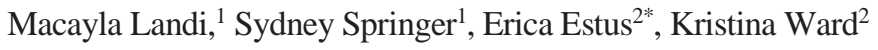

${ }^{1}$ Macayla Landi and Sydney Springer, URI College of Pharmacy 2015 PharmD candidates at time of writing ${ }^{2}$ Erica Estus, PharmD, CGP and Kristina Ward, PharmD, BCPS are Clinical Associate Professors at URI College of Pharmacy

*Corresponding Author: Erica Estust, PharmD, CGP, University of Rhode Island, 7 Greenhouse Road, Kingston, RI 02881; Office: (401) 874-7638; Fax: (401) 874-2717; email: elestus@uri.edu

Disclosure: No funding was received for the development of this manuscript. The authors have no potential conflicts of interest

Key Words: Critical appraisal, Journal club, Medical literature, Pharmacy student, Student-run

Abbreviations: APPE $=$ Advanced Pharmacy Practice Experi- ence, ASCP $=$ American Society of Consultant Pharmacists, DI = Drug information, IAL = Interactive Learning, IM = Internal medicine, P3 = Third professional year pharmacy student, P4 = Fourth professional year pharmacy student, URI = University of Rhode Island.

\begin{abstract}
:
After attending an educational session on hosting journal clubs at the 2013 Annual Meeting \& Exhibition, American Society of Consultant Pharmacists, Seattle, Washington, two third-year professional pharmacy students created a student-run journal club through the University of Rhode Island's ASCP student chapter. Three journal club sessions were held during the spring semester and were open to all pharmacy students. Students completed an anonymous pre- and post-survey to assess confidence in evaluating medical literature. Of the 18 participants, 5 were lost to follow-up. Significant improvements were found among all participants in their confidence in critically evaluating clinical research, interpreting statistical methods, and completing a journal club during Advanced Pharmacy Practice Experience rotations. This activity can be replicated in academic settings as well as workplace environments where pharmacy students are involved.
\end{abstract}

Consult Pharm 2015;30:356-60. 
A journal club is a group of individuals who meet regularly to critically appraise the clinical application of medical literature. Journal clubs have an extensive history in medical education and it is believed that the first formal journal club was held in 1875 at McGill University in Montreal, Canada. Journal clubs have become an important educational practice and have changed over the years to meet the needs of the participants. However, three objectives have remained the same: to keep up with current medical literature, to influence clinical practice, and to teach critical appraisal skills. ${ }^{1}$

\section{Introduction}

Many practitioners have difficulty finding, assessing, interpreting, and applying current best evidence. Journal clubs are used to critically evaluate the clinical application of recent research articles in the medical literature. Participation of health care providers in journal clubs is important to the successful application of evidence-based research to clinical practice.

The 2013 report by the Center for Advancement of Pharmaceutical Education on educational outcomes recommends that all doctor of pharmacy students be able to "develop, integrate, and apply knowledge from the foundational sciences (pharmaceutical, social/behavioral/ administrative, and clinical sciences) to evaluate the scientific literature" and ultimately advance "patient- centered care." $\mathrm{A}$ majority of pharmacy programs across the nation incorporate journal clubs into their advanced pharmacy practice experience (APPE) rotations to improve the critical appraisal skills of their students. ${ }^{3}$

In a study conducted at Long Island University's Arnold and Marie Schwartz College of Pharmacy, Brooklyn, New York, fourth-year pharmacy (P4) students completed three journal clubs during their internal medicine (IM) and drug information (DI) APPE rotations. ${ }^{3}$ On a 21-item survey used to evaluate the student's perception of the value of journal clubs and their ability to complete them, students who completed their DI rotation first ranked their understanding of study designs and statistical analysis higher than their peers who completed their IM rotations first. Additionally, those who completed their DI rotation first had a significantly higher learning slope when comparing mean grades on a standardized rubric. $^{3}$ Two major themes arose from the study: Students felt their academic experience did not adequately prepare them for journal clubs during their APPE rotations, and a majority of students indicated they preferred informal group discussions over formal presentations of journal articles. ${ }^{3}$

Early exposure of students to journal clubs during their pharmacy education is an education tool that can improve students' ability to interpret up-to-date clinical evidence and apply it to practice. The University of Rhode Island (URI) College of Pharmacy offers didactic training in a required Drug Information and Analysis of Literature course, where students are introduced to biostatistics and study methodology and how each relates to medical literature and journal club activities. Critical appraisal skills are then cultivated through journal clubs during an Interactive Learning (IAL) course, which is offered every semester throughout the professional program. Each IAL section has a small class size of 10 to 12 students to allow for active participation and discussion.

The purpose of this study was to determine if a newly implemented student-run journal club was able to improve pharmacy students' confidence in critically evaluating medical literature and participating in a journal club.

\section{Methods}

After attending an educational session on hosting journal clubs at the 2013 Annual Meeting \& Exhibition of the American Society of Consultant Pharmacists (ASCP) conference in Seattle, Washington, two third professional year (P3) pharmacy students were inspired to begin a student-run journal club through the URI ASCP student chapter. Discussion and planning occurred over several weeks, and the first session took place in March 2014. Two sessions followed during the same 2014 spring semester. Each session was well attended and represented by a variety of class years ranging from sophomores through P3 
students. Two P4 students facilitated each journal club along with a pharmacy practice faculty member. Journal club topics ranged from vitamin D insufficiency and its effect on insulin sensitivity to donepezil and memantine in Alzheimer's disease. With a wide variety of topics and presenters, student attendees were able to participate in and observe different styles and techniques used to present a journal article.

An e-mail was sent out early in the Spring 2014 semester with the dates of each journal club session to the URI ASCP listserv. Prior to each journal club session, a reminder e-mail containing the selected article along with a journal club template, which addressed components of the article to be appraised, were sent out one week prior to scheduled journal club sessions (Table 1). Food was offered as an incentive at each session and served to create a more relaxed environment. Participants were asked to complete an anonymous 18 -item survey during the first and last journal club session. This project was deemed exempt research by URI's Investigational Review Board. Pre- and post- surveys were identical and assessed the students' confidence in evaluating medical literature. A deidentified code was used to link the pre- and post-survey of each participant to conduct analyses.

The primary outcome measure was change in pharmacy students' confidence in critically evaluating medical literature. Data analysis was done using one-sided Wilcoxon rank sum with subgroup analysis based on number of sessions attended and current professional year. All analyses were conducted on SAS software 9.3 (SAS Institute Inc., Cary, NC, USA).

\section{Results}

Of the 18 participants, 5 were lost to follow-up. Significant improvement in the primary endpoint of confidence in critically evaluating clinical research was found among all participants. Improvements in interpreting statistical methods and confidence in completing a journal club during APPE rotations also improved. All students showed significant improvement in interpreting basic components of journal clubs, including: $P$-values, confidence intervals, study power, study limitations, interventions, funding, and results (Table 2).

Based on subgroup analysis, the greatest improvements were seen when asked about confidence in critically evaluating a clinical research study, with significant improvements seen in first professional year students $(P=0.01)$ and P3 students $(P=0.04)$. Students who attended three sessions showed an improvement in appreciation of the educational value of journal clubs $(P=$ $0.01)$, which was in contrast to those who attended two $(P=0.5)$ or one session $(P=0.79)$. P3 students reported improvements in confidence completing journal clubs during APPE rotations $(P=0.02)$ in comparison with first- and second-year professional students.

\section{Discussion}

Students who attended at least two student-run journal club sessions showed a significant increase in confidence in the ability to critically evaluate medical literature. Students' confidence in interpreting components of a journal club and critical appraisal skills also significantly improved. No significant difference was observed among students in their confidence in applying the information clinically. However, this may be because students participated from various professional years, and the clinical experience levels of the individual students at this early point in their pharmacy education varied and may not have been a result of the format of the student-run journal club. Students were asked to describe their experience following the conclusion of the three journal club sessions. The following are a sample of student testimonials:

"The relaxed environment is beneficial to my learning because I know that the questions I ask are also questions of other students." - P3 pharmacy student

"Having a student-led journal club has immensely helped my ability to evaluate medical literature. URI College of

Pharmacy has a great course on the analysis of literature, but there were limited opportunities to apply our skills in the 
classroom. Being able to practice the skills needed to evaluate literature with peers in a relaxed environment has been great. It is also easier to ask questions in this setting. I feel more prepared and confident for the journal clubs I will do on my future rotations."

- P3 pharmacy student

"By participating in journal club outside the classroom, I feel that I'll be comfortable successfully completing journal clubs on APPE rotations."

- P3 pharmacy student

Limitations of the study included the small sample size and the number of students lost to follow-up. Sessions were planned around pharmacy exams; however, because of the wide range of years represented, a large number of students were unable to attend more than one session. Though students were encouraged to reach out to their non-ASCP member peers, using the URI ASCP's listserv limited the number of students who had access to important information pertaining to each journal club.

Despite the limitations, an improvement in confidence was observed, and the small sample size allowed for a real life "journal club atmosphere." While not the intention of the original study a smaller group size may have also encouraged team-based learning through open discussion during these informal sessions, which resulted in enthusiastic participation. Implementation of a team- based approach may be a consideration for future projects, particularly if participation rates increase.

\section{Implications}

The student-run journal club is being continued during the 2014-2015 school year, headed by two new student pharmacist members of ASCP, with a goal of meeting monthly. This approach to conducting a journal club may be beneficial to pharmacy students over the traditional learning model, in which students passively receive information about the analysis of literature from an instructor. This activity can be replicated in academic settings as well as workplace environments where pharmacy students are involved.

\section{References}

1. Linzer M. The journal club and medical education: over one hundred years of unrecorded history. Postgrad Med J 1987;63:475-8.

2. Medina MS, Plaza CM, Stowe CD et al. Center for the Advancement of Pharmacy Education (CAPE 2013) Educational Outcomes. Am J Pharm Educ 2013;77:162, doi: 10.5688/ajpe778162.

3. Arif SA, Gim S, Nogid A et al. Journal clubs during advanced pharmacy practice experiences to teach literature-evaluation skills. Am J Pharm Educ 2012;76:88. doi: 10.5688/ajpe76588. 
Table 1. Elements of the journal club template

- Study background

- Previous trials

- Study justification

- Null hypothesis

- Study overview

- Funding

- Trial design

- Objectives

- Methodology

- Inclusion/exclusion criteria

- Interventions

- Primary/secondary endpoints

- Statistical Analysis

- Results

- Enrollment

- Baseline characteristics

- Monitoring

- Primary/secondary outcomes

- Other clinical events

- Author conclusions

- Generalizability/critique/discussion 
Table 2. Changes in Pre- and Post-Survey Responses $(\mathbf{N}=13)$

\begin{tabular}{|c|c|c|}
\hline Question & A/SA Before (\%) & A/SA After (\%) \\
\hline I am confident in my abilities to critically evaluate a clinical research study. & 7.7 & $84.6 * *$ \\
\hline I am confident in my abilities to interpret confidence intervals. & 23.1 & $84.6 * *$ \\
\hline $\begin{array}{l}\text { I am confident in my abilities to interpret } \mathrm{P} \text {-values and understand their } \\
\text { meaning. }\end{array}$ & 46.2 & $92.3 *$ \\
\hline I am confident in my abilities to interpret a study's power. & 23.1 & $84.6 * *$ \\
\hline $\begin{array}{l}\text { I am confident in my abilities to interpret statistical methods in a clinical } \\
\text { research study. }\end{array}$ & 7.7 & $61.6^{* *}$ \\
\hline $\begin{array}{l}\text { I understand how to interpret interventions and their effects on the clinical } \\
\text { research study's results. }\end{array}$ & 53.9 & $92.3 * *$ \\
\hline $\begin{array}{l}\text { I understand the differences between primary and secondary outcomes and } \\
\text { their implications for the clinical research study's results. }\end{array}$ & 76.9 & $100 * *$ \\
\hline $\begin{array}{l}\text { I am confident in my abilities to determine limitations of a clinical research } \\
\text { study. }\end{array}$ & 53.9 & $84.6 * *$ \\
\hline $\begin{array}{l}\text { I understand the differences between a null hypothesis and an alternative } \\
\text { hypothesis }\end{array}$ & 38.5 & $92.3 * *$ \\
\hline $\begin{array}{l}\text { I understand how inclusion and exclusion factors relate to clinical research } \\
\text { study results. }\end{array}$ & 92.3 & $92.3^{*}$ \\
\hline $\begin{array}{l}\text { I understand how baseline characteristics of the population may affect the } \\
\text { clinical research study's results. }\end{array}$ & 84.6 & $100^{*}$ \\
\hline $\begin{array}{l}\text { I am confident in my abilities to determine if an appropriate intervention was } \\
\text { implemented. }\end{array}$ & 23.1 & $77 * *$ \\
\hline I am confident that I can interpret how funding may implicate the study. & 84.6 & $92.3 * *$ \\
\hline $\begin{array}{l}\text { I am confident that I will be able to concisely and accurately describe the } \\
\text { results of a clinical research study. }\end{array}$ & 38.5 & $84.6 * *$ \\
\hline $\begin{array}{l}\text { I am confident in my abilities to interpret clinical applications of a clinical } \\
\text { research trial's results. }\end{array}$ & 46.2 & 69.2 \\
\hline $\begin{array}{l}\text { I am confident that I will be able to complete a journal club during my } \\
\text { Advanced Pharmacy Practice Experience rotations. }\end{array}$ & 15.4 & $84.6 * *$ \\
\hline I can appreciate the educational value of a journal club. & 100 & 100 \\
\hline
\end{tabular}

Abbreviations: A = Agree, $\mathrm{SA}=$ Strongly agree.

$* \mathrm{P}<0.05$.

$* * \mathrm{P}<0.01$. 